\title{
Reforming Pension Funds in Sri Lanka: International Diversification and the Employees' Provident Fund
}

\author{
by \\ Ajantha Sisira Kumara \\ National Graduate Institute for Policy Studies (GRIPS) \\ 7-22-1 Roppongi, Minato-ku, Tokyo 106-8677, Japan \\ mhasisira@yahoo.co.uk \\ and \\ Wade Donald Pfau \\ Associate Professor, National Graduate Institute for Policy Studies (GRIPS) \\ 7-22-1 Roppongi, Minato-ku, Tokyo 106-8677, Japan \\ wpfau@grips.ac.jp
}

\begin{abstract}
The Employees' Provident Fund (EPF) of Sri Lanka is a defined-contribution pension fund whose pooled asset holdings consist mainly of local government bonds. Regulations prohibit international diversification, and this paper aims to quantify the extent of the potential harms, if any, caused by this constraint. To improve the robustness of the findings, we use two distinct methodologies. These include traditional mean-variance analysis from modern portfolio theory, and Monte Carlo simulations that estimate the distribution of wealth accumulated at retirement from the contributions of a hypothetical worker. Both methods produce qualitatively and quantitatively similar results: workers with risk aversion varying from aggressive to conservative will be better served by allowing international diversification. The results are particularly persuasive for the second approach. The EPF fund managers will likely behave fairly conservatively toward risk, which suggests that around half of the fund assets should be invested abroad.
\end{abstract}

Keywords: International Diversification, Utility Maximization, EPF, Hypothetical Worker, Modern Portfolio Theory, Sri Lanka

JEL Classification Codes: G11, H55, G23

Acknowledgements: The authors are grateful for financial support from the Japan Society for the Promotion of Science Grants-in-Aid for Young Scientists (B) \#20730179. 


\section{Introduction}

The retirement benefits in defined-contribution (DC) pension plans are not guaranteed and depend on the investment performance of the fund. Choosing appropriate asset allocation strategies is one of the core functions that any pension fund or provident fund must perform to enhance investment performance (Ross, 2004). Moreover, Chan-Lau (2005) argues that investment regulations and international diversification of their portfolios play a pivotal role in determining the investment performance of a pension fund.

The Employees' Provident Fund (EPF) of Sri Lanka, the largest DC plan for the country's formal sector, is searching for suitable reforms to strengthen its investment performance. Investment policies and performance of the EPF remain a challenge in Sri Lanka due to the limitations of domestic financial markets, tight government restrictions on portfolio allocation including the prohibition of international assets, and low importance given to fiduciary responsibilities. The EPF has suffered from low rates of return over the last few decades in spite of the parametric reforms implemented from time to time by the fund management to rectify the situation.

The rapid aging of the country's population, rapidly growing pension fund, and continuously low member benefits require more than parametric reforms. Reforming the investment policy of the fund is essential. Karunarathne (2005) points to a promising direction for reform: the Sri Lankan EPF should search for possible mechanisms to diversify pension assets abroad. It is worthwhile to analyze the possible consequences of such action. Accordingly, the objectives of this study are to analyze how the returns and risks, and ultimately the members' retirement benefits, will be impacted by international diversification.

Whether to allow international investment for DC pension schemes is being debated by governments in industrial and developing countries alike. Generally, modern portfolio theory, starting with Markovitz (1952) and Roy (1952), predicts that portfolio diversification across asset classes with loosely correlated returns increases portfolio return for a given level of risk or even for lower risk. As argued by Asher (2008), the allocation of pension fund assets, especially in Asian countries, is excessively influenced by tight government regulations that do not necessarily benefit members. Pension funds have become biased toward overweighting government securities and 
other domestic assets rather than using optimal asset allocation strategies. This may lead to suboptimal portfolio holdings with lower returns and higher risks, and deteriorating retirement benefits for members. For example, Pfau (2009) quantifies that including world assets could help a great deal in improving the sustainability of Pakistan pensions by simultaneously increasing the expected return and decreasing volatility.

Investment constraints make pension schemes inflexible and unable to accommodate rapid changes in financial conditions or structural changes in financial markets. According to Solnik and McLeavey (2009), international assets tend to provide diversification benefits because they are not exposed to country-specific shocks. Practically speaking, the underdeveloped nature of domestic financial sectors and rapidly growing pension funds in developing countries provide a good reason for considering world assets. The asset prices of such underdeveloped financial markets are distorted and exposed to higher risks and potentially more frequent asset price bubbles. However, there are also justifications for investment restrictions on world assets. According to Bodie and Merton (2002), domestic investment of pension funds may reduce the risk of financial outflows. Pension funds can be invested domestically to enhance employment opportunities for domestic workers rather than for workers elsewhere. Also, the higher transaction costs and currency risk involved in international investments may offset any potential diversification benefits (see Reisen, 1997; and Bodie and Merton, 2002). Further, pension funds may generate externalities through stimulus for financial sector development. The pension fund's domestic investment raises the supply of long-term funds, stimulating the financial infrastructure and promoting national savings. However, cross-country evidence shows little support for the claim that the accumulation of pension assets would provide externalities for financial sector development (Reisen, 1997). Further, Bodie and Merton (2002) show that pension funds can diversify internationally using asset swaps without hurting the development of local capital markets.

We organize the study as follows. We first provide an overview of existing pension schemes in Sri Lanka. Then we analyze the current investment portfolios and investment performance of the EPF. After discussing the methodology and data, we provide our results, which include an analysis of optimal asset allocation based on different levels of risk aversion using historical data, and an analysis of the impact of 
investment restrictions, using two distinct methodologies. We find evidence to support the inclusion of world assets in the EPF, suggesting that the current investment policy should be liberated. Without world assets, investors potentially experience smaller portfolio returns, though this would be accompanied by a reduction in risk. Our utility maximization approach indicates, though, that investors across the risk spectrum will be better off with a more diversified portfolio. The simulation results for the hypothetical worker also reveal that retirement benefits could be increased by including world assets in the EPF's investment portfolio, and with this framework the increase in downside risk is negligible.

\section{The EPF of Sri Lanka: Background, Investment Portfolio and Performance}

The EPF, which is the largest social security scheme in Sri Lanka in terms of asset size and membership, was established according to the Act No. 15 of 1958 in order to cover employees in the formal sector. The system provides retirement benefits to private sector and cooperative sector employees who are not entitled to other public sector pensions. This is a fully funded, mandatory scheme in which the employer and the employee pay a defined contribution into a pooled fund which is invested and paid back with accumulations to the employee, usually in the form of a lump-sum payment, at retirement. The current contribution rates from the employee and the employer stand at eight per cent and 12 per cent of the employee's gross salary, respectively. The administration of the fund is handled by the Department of Labor, while the fund is managed by the Central Bank of Sri Lanka.

\section{//Table 1 About Here//}

Table 1 shows the asset allocation of the EPF and its nominal and real rates of return on average investment. EPF investment was predominantly in the form of rupee loans in which the interest rate is administered by the Central Bank (not market forces) until the late 1990s, when a shift toward treasury bonds as the dominant asset began. Throughout the period from 1985 to 2008, the total investment in government securities has been more than 97 per cent. Though the fund started investing in the domestic equity market in 1998, amounts allocated to stocks have been negligible. Further, the investment portfolio does not hold any international assets due to the restrictions imposed by the fund management. Other assets, including corporate debentures, call money, repurchase agreements, and commercial paper, account for a minor portion of EPF assets. 
Table 1 also shows nominal returns compared to a benchmark, as well as real returns. The benchmark is defined as a weighted average of returns to rupee loans, treasury bills, and treasury bonds, where the weights are defined by the fund's asset allocation for the year. Since these are the primary fund assets, the purpose is to show whether fund managers are able to meet reasonable return targets, given their asset allocation decisions. The "difference" column shows that the answer is generally yes, as fund managers at least are not under-performing within their chosen allocation targets. Nonetheless, the compounded real returns through the period averaged only 2.1 percent. As argued by Kanakaratnam and Yin (2004), the low rate of return experienced by the EPF of Sri Lanka has led it to accrue insufficient member balances, exposing members to financial difficulties after retirement.

\section{//Figure 1 About Here//}

Figure 1 depicts the total EPF portfolio size and the market capitalization of stocks as a percentage of GDP for the period from 1995 to 2009. The total EPF investment portfolio has been increasing and currently is approximately 30 per cent of GDP. The time series data for the market capitalization of the domestic equity market show greater volatility, and more importantly, from 1996 to 2003 continuously, and recently again in 2008, the total size of the EPF was larger than the market capitalization of the Colombo stock market. For instance, in 2000, the EPF was 13.7 per cent of GDP (214.8 LKR Billion), while the market capitalization of the Colombo stock market was 5.6 per cent of GDP (88.8 LKR Billion). In addition, the government and corporate bond markets in Sri Lanka are quite small and underdeveloped with only a few players. The EPF has limited opportunities for investing in diversified asset classes in Sri Lanka due to its size and the underdeveloped nature of the domestic financial and capital markets.

The investment decisions of the EPF are taken by the Monetary Board of Sri Lanka's Central Bank. Managing government debt is also undertaken by the same unit. Karunarathne and Goswami (2002) argue that these two roles conflict with each other. The Monetary Board is expected to maximize returns to the members in their role as fund managers, but it is also expected to finance government debt at the lowest cost. Thus, it is worthwhile reviewing the current investment strategies of the EPF and searching for suitable reforms.

\section{Methodology}


To improve the robustness of the findings, we employ two distinct methodologies to determine the optimal asset allocation for the EPF. As a starting point, we employ the standard mean-variance portfolio selection framework to determine the optimal unconstrained and constrained portfolios and associated portfolio returns and risks. The optimal portfolio is a portfolio on the efficient frontier that maximizes the EPF member's utility with the best combination of expected returns and risk (measured as the standard deviation of asset returns). For each asset class, inputs into the optimization include the mean return, standard deviation of returns, and the correlations with other asset classes. First, we construct unconstrained portfolios by considering five broad asset classes for different levels of risk aversion: Sri Lankan treasury bills, Sri Lankan stocks, world bills, world bonds, and world stocks. Then, portfolios are constrained to exclude world assets and new optimal asset allocations are found. This allows for a discussion of how portfolio returns and risks are impacted due to the investment constraints imposed on the world assets.

According to the standard mean-variance framework, investors select a portfolio which maximizes their utility $\left(U_{p}\right)$ defined as:

$$
U_{p}=r_{p}-0.005 A \sigma_{p}^{2}
$$

where $r_{p}$ and $\sigma_{p}$ are the expected return and the expected standard deviation of the portfolio, respectively, and $A$ is the investor's risk aversion coefficient on which the acceptable tradeoff between risk and return is based. We use values for $A$ ranging from one to 10 in this study. Typically, an aggressive investor is believed to have a value of one or two, a moderate investor has about three, and a conservative investor could range from five to 10, or even more. Because the EPF is a pooled fund, the risk aversion coefficient will need to represent a compromise among all of the fund participants, and pension funds are typically assumed to be somewhat risk averse with a coefficient value of around five.

This mean-variance framework does have drawbacks, the most relevant being that it is intended for single-period optimization, rather than the long-term optimization required by a maturing pension fund. Small changes in the inputs can also result in dramatic changes to suggested asset class weights. Therefore, we also use a Monte Carlo simulation for a hypothetical worker to determine the optimal unconstrained and 
constrained asset allocations based on the expected utility of wealth accumulated at retirement. The results generated through Monte Carlo simulation reflect forecast uncertainty by generating thousands of plausible scenarios from the inputs of means, standard deviations, and correlations.

Our hypothetical worker starts with a gross salary of LKR 200,000 per year, which is assumed to grow by one per cent in real terms each year during a 35-year career profile. This worker enters the workforce on her $21^{\text {st }}$ birthday and retires on her $55^{\text {th }}$ birthday. In line with the current EPF regulations of Sri Lanka, 20 per cent of her gross salary is deposited in her EPF member account for each year of employment. We further assume that there will be an annual administrative fee of 0.3 per cent for domestic investments and 0.5 per cent for international investments charged by the EPF. These rates are likely on the low end of possible expenses. All the stock dividends and interest payments are assumed to be free from income taxes and reinvested. In order to maintain the same asset allocations over time, the investment portfolios will be rebalanced at the end of each year.

We determine optimal asset allocation strategies by calculating the distribution of terminal wealth accumulation for the hypothetical worker for a variety of asset allocation strategies. Each asset can vary in five percentage point increments from zero to 100 per cent, such that there are a total of 9,113 unconstrained portfolio strategies for five assets and 21 constrained portfolio strategies for two domestic assets. We simulate 10,000 scenarios, each of which consists of real returns for five assets over a 35-year period. With the distribution of terminal wealth accumulations, we estimate the expected utility using a standard constant relative risk aversion (CRRA) utility function:

$$
E\left[u\left(w_{i}\right)\right]=\sum_{i=1}^{N}\left(\frac{1}{1-\gamma} w_{i}^{1-\gamma}\right)
$$

where $w_{i}$ represents the wealth accumulation at retirement in each of $\mathrm{N}=10,000$ simulations. The variable $\gamma$ is the investor risk aversion coefficient which we consider for a range from one to 10. A value of zero represents risk neutrality. Increasingly positive values indicate increasing risk aversion and in the case that $\gamma=1$, the utility is 
defined as the natural logarithm of wealth ${ }^{1}$. As mentioned before, since the EPF is a pooled fund, the appropriate risk aversion coefficient must balance the needs and attitudes of all the stakeholders. This is a standard way to evaluate the utility generated by wealth as it provides a way to account for diminishing utility gains as wealth increases (see for instance, Ibbotson et al., 2007). We estimate the expected utility for each strategy under each level of risk aversion by taking the mean utility from the 10,000 simulations. The optimal asset allocation for each level of risk aversion is the strategy that provides investors with the highest mean utility. This process is followed for selecting the optimal unconstrained (with world assets) and constrained portfolios (without world assets).

To demonstrate the performance of the optimal asset allocation, we calculate nest-egg ratios for the unconstrained and constrained investment strategies. Following Pfau and Atisophon (2009), the nest-egg ratio is calculated as the ratio of accumulated assets at retirement to the average of the five years of income before retirement. The impacts of investment constraints are discussed by comparing the distribution of nest-egg ratios with and without world assets.

\section{Data}

For both estimation methods, we use annual data for the returns at year end from 1991 to 2007 for two domestic assets and three world assets. Taking domestic assets first, the treasury bill returns are a weighted average yield per annum determined in the primary market for one-year bills. These data have been obtained from the Central Bank of Sri Lanka. Equity returns include both capital gains and dividends. The percentage change in the Milanka Price Index of the Colombo Stock Exchange (CSE) shows the capital gains, and we add dividend yields to the capital gains to get the total return for each year. This data is from the CSE. These return indices do not include any transaction costs. Rupee loans (introduced in the early 1950s) and Treasury Bonds (introduced in 1997) are two other debt instruments used by the government of Sri Lanka. The Treasury Bond market in Sri Lanka began too recently to provide adequate data, while the rates

\footnotetext{
${ }^{1}$ By L'Hôpital's Rule $\quad \lim _{\gamma \rightarrow 1} \frac{w^{1-\gamma}}{1-\gamma}=\ln (w)$
} 
of return on Rupee loans are administratively fixed and difficult to forecast appropriately. Hence, we ignore those two domestic assets for the current analysis.

World assets, including the returns for world bills, world bonds, and world stocks, are available in US dollar terms from Morningstar. This is the updated dataset described in Dimson, Staunton, and Marsh (2002). World assets are defined as an index of 17 developed market countries weighted by country size. As for other relevant data in Sri Lanka, inflation is defined as the percentage change in the 12-month moving average of the Colombo Consumers' Price Index (CCPI), while the exchange rate is defined as the amount of US dollars that can be purchased with one Sri Lankan Rupee. The Central Bank of Sri Lanka is the data source for inflation and exchange rates. Since we assume that the EPF will not hedge currency risk, the returns on world assets are converted into Sri Lankan Rupees using the exchange rate data. The inflation data enable us to compute real returns for the assets.

\section{Results}

\section{Characteristics of Historical Economic Data}

//Table 2 About Here//

Table 2 provides summary statistics for historical asset returns and other economic data. First in nominal terms, Sri Lankan stocks reported a mean 18.02 per cent return with a standard deviation of 33.95 per cent. One-year Sri Lankan treasury bills earned a mean nominal return of 14.66 per cent with a much lower standard deviation of 4.24 per cent. Unhedged returns from world assets are calculated using exchange rate data. The Sri Lankan Rupee depreciated at an average rate of 5.73 per cent per year with a standard deviation of 3.67 per cent. One USD could buy 41.37 LKR at the end of 1991 and 110.62 LKR at the end of 2007. As such, unhedged returns for world assets in Sri Lanka were higher than their USD values.

In terms of LKR, world stocks earned a mean nominal return of 17.4 per cent with a standard deviation of 15.3 per cent, showing a slightly smaller return but much less volatility compared with Sri Lankan stocks. In terms of compounded geometric returns, unhedged world stocks performed the best. Unusually, the exchange rate risk for unhedged world stocks actually served to reduce their volatility slightly. This is because the USD returns on world stocks were positively correlated with strengthening rupee (correlation coefficient $=0.416$ ), reducing both the upside and downside of returns in 
LKR. On average, world bills earned an unhedged nominal return of 10.47 per cent with a standard deviation of 4.97 per cent. When compared with the Sri Lankan Treasury bill market, the world bill market exhibited lower returns and higher volatility. World bonds earned a mean unhedged nominal return of 16.26 per cent with a standard deviation of 10.45 per cent during the concerned period. The mean unhedged nominal returns for world bills, world bonds, and world stocks were greater than the corresponding mean hedged nominal returns by $6.5,6.79$, and 6.64 percentage points, respectively, due to currency depreciation.

Table 2 also provides the same summarized statistics for real asset returns adjusted for domestic inflation. Domestic inflation averaged 10.45 per cent with a standard deviation of 3.55 per cent. Real asset returns also showed the same historical trends as nominal asset returns. For instance, in terms of real returns, the Sri Lankan stock market showed the highest volatility with a mean real return of 6.76 per cent and a standard deviation of 30.01 per cent. World stocks experienced half the volatility of domestic stocks, but only a slightly smaller return.

Table 2 also shows the correlations between assets for both nominal and real returns. Correlations are generally low between all the assets, with the highest correlations occurring between Sri Lankan and world bills, and between world bonds and world bills. But even the highest correlation of 0.414 will allow for diversification benefits, and all of the assets may serve to complement one another in the portfolio.

\section{Optimal Asset Allocation and the Costs of Constraints for Mean-Variance Analysis}

Table 3 shows details of the optimal asset allocation from mean-variance analysis for portfolios including world assets for varied levels of risk aversion. The calculations are shown for both nominal and real economic data. Because the results are qualitatively and quantitatively quite similar, our discussion focuses on the results using nominal data.

\section{//Table 3 About Here//}

Table 3 shows that more aggressive investors can potentially earn a higher return by accepting greater risks. For instance, the most aggressive investor, whose coefficient of risk aversion is one, could earn 17.16 per cent with volatility of 11.27 per cent. This investor's optimal portfolio includes 87.96 per cent world assets and 71.91 per cent stocks. The largest allocation in this portfolio is for world stocks (59.87 per cent), followed by world bonds (28.09 per cent) and Sri Lankan stocks (12.04 per cent). Sri 
Lankan bills and world bills do not play a role for this investor and it will remain the case that world bills are not included in any optimal portfolios.

When risk aversion increases, the portions of the portfolio dedicated to both world assets and to stocks gradually decline. However, even the most conservative investor we consider, whose coefficient of risk aversion is 10 , could expect to earn 15.53 per cent with volatility of 4.2 per cent by maintaining 34.72 per cent in world assets. As risk aversion increases, more specifically, Sri Lanka bills grow in importance, while the role of both local and world stocks declines. World bonds, on the other hand, experience an increasing role for moderate investors, before declining in favor of Sri Lanka bills for the most conservative investors. It is important to note that the optimal unconstrained portfolios include more than 80 per cent world assets for the investors whose coefficients of risk aversion are one, two or three. As well, for all levels of risk aversion, the recommended total allocation to international assets always exceeds the recommended allocation to stocks. For a risk aversion coefficient of five, a conservative value typical of pension funds, mean-variance analysis suggests an optimal allocation of 55 per cent to world assets.

\section{//Table 4 About Here//}

Table 4 shows the impact of prohibiting world assets from the EPF investment universe, in terms of the percentage change in potential returns and risks. These computations are provided for varying coefficients of risk aversion for both nominal and real data. As a consequence of prohibiting world assets, both potential portfolio returns and risks are reduced at all levels of risk aversion. Though risk is less as well, these results do represent a decrease in investor utility because the unconstrained results show how investors would maximize their utility, given their risk aversion. We can be sure that the additional risks in the unconstrained case were an acceptable tradeoff to receive a chance for the greater returns, or investors would have not chosen the unconstrained portfolio in the first place. For nominal data, the constraints reduce returns by between about four and 10 per cent, and reduce risks by between about four and 36 per cent.

\section{Optimal Asset Allocations and the Costs of Constraints for the Hypothetical Worker}

The Monte Carlo simulation approach for a hypothetical worker provides a completely different methodology, as described earlier, to check the robustness of the meanvariance analysis findings. 


\section{//Table 5 About Here//}

Table 5 provides simulation results for the unconstrained asset allocation strategies. The top part of the table includes the percentages invested in each of five assets and the summarized information on percentage invested in stocks and world assets at the optimal portfolio for varied levels of risk aversion. In order to evaluate pension benefits in terms of assets accumulated at retirement, nest-egg ratios for each optimal investment strategy have been calculated. Details about the distribution of nest-egg ratios for the utility-maximizing strategy for each risk aversion coefficient are also provided in the table.

For an investor seeking to maximize the expected utility from their accumulated wealth at retirement, Table 5 shows that international diversification plays an important role in the optimum portfolios. International assets account for 80 percent or more of the portfolio for risk aversion coefficients less than or equal to 4, and they account for 65 and 35 percent, respectively, for risk aversion of 5 and 10 . With a risk aversion coefficient of 5, the optimal portfolio consists of 35 percent world bonds, 30 percent world stocks, 25 percent domestic bills, and 10 percent domestic stocks. Domestic stocks do not account for more than 20 percent of the portfolio in any of the cases shown, and domestic bills only become important for more conservative investors. Aggressive and moderate investors mostly rely on world stocks and world bonds.

These optimal portfolios are chosen because they maximize the expected utility for the distribution of retirement wealth across the 10,000 simulations, and the remainder of Table 5 presents details about these distributions, scaled as the nest-egg ratios of accumulated wealth to the average of the final five years of worker salary. What these numbers demonstrate is that more conservative investors are willing to forgo higher wealth accumulations at the top end of the distribution, because they place more weight on avoiding particularly bad outcomes on the low end of the distribution. As such, through the $10^{\text {th }}$ percentile of the distribution, nest-egg values are higher as risk aversion increases, but above the median, accumulations are lower as risk aversion increases. Using a typical rule of thumb that retirees may safely withdraw 4 percent of their wealth accumulation at retirement, adjusted in subsequent years for inflation, the median nestegg ratios imply that, on average, the EPF would provide for a real retirement income that replaces 50 to 60 percent of their pre-retirement earnings. But risks are present, as 
for the conservative investor with risk aversion of 5 , the $5^{\text {th }}$ percentile nest-egg ratio of 9.39 implies that only about 38 percent of pre-retirement income can be replaced with a 4 percent withdrawal rate.

\section{// Table 6 About Here //}

Table 6 complements Table 5 by showing the impact on asset allocations and the distribution of wealth accumulations for the optimal asset allocations when the EPF is constrained from diversifying internationally. In choosing only between domestic stocks and bills, we can be sure that EPF members reduce their utility, because otherwise they could have chosen the constrained portfolio in the unconstrained case. But if this explanation proves unsatisfactory, the impacts on the accumulated wealth distributions shown in Table 6 much more persuasively support international diversification. As shown with the mean-variance analysis, for a single-period optimization, the constrained portfolios did allow for noticeably less risk, but now over a 35-year horizon, the lower risk of the constrained portfolios is miniscule in nature. Actually, first of all, for the risk aversion coefficient of one, the unconstrained optimum stochastically dominates the constrained optimum. In other words, across the entire distribution of outcomes, the internationally diversified portfolio provides a larger nestegg ratio. In the other cases, the unconstrained portfolio does not stochastically dominate, but it comes close. For a risk aversion of 5, we find that for the first percentile of the distribution, the constrained portfolio provides a nest-egg ratio of 8.44, which is 5.24 percent larger than the 8.02 value in the unconstrained case. However, by the fifth percentile of the distribution, the constrained nest-egg ratio is already 1.28 percent less, and across the remainder of the distribution, the nest-egg ratios from the constrained optimum fall increasingly behind the unconstrained optimum. We already know from the utility calculations that the unconstrained portfolio provides more utility, and a comparison of these distributions provides excellent intuition for why this is the case, as someone would clearly need to be incredibly risk averse to prefer having slightly more wealth in the worst outcomes occurring less than 5 percent of the time, knowing that the tradeoff is experiencing increasingly less wealth the rest of the time. For risk aversion of 10 , the constrained portfolio provides more wealth in less than one percent of the outcomes. 


\section{Conclusion}

Starting with the mean-variance framework and later employing a hypothetical worker approach, we quantify the impacts of including world assets in the EPF of Sri Lanka. We find that higher returns, leading to higher levels of asset accumulation for most of the distribution, could be expected by including world assets in the EPF's investment portfolio. Under various circumstances and assumptions, the most conservative optimal portfolios are expected to consist of more than 25 per cent of world assets. Accordingly, our findings present evidence to at least consider liberalizing the current investment policy of the EPF. We have not exhausted the list of possible assets to be included in EPF portfolios, as this paper tries to demonstrate possible impacts of international diversification rather than giving a finalized recommendation for asset allocation. 


\section{References}

Asher, M.G. (2008) Social Security Reform Imperatives in Developing Asia. The Indian Economic Journal, Vol.56, No.1, pp.114-125.

Bodie, Z. and Merton, R.C. (2002) International Pension Swaps. Journal of Pension Economics and Finance, Vol.14, No.3, pp.107-134.

Chan-Lau, J. (2005) Pension Funds and Emerging Markets. Financial Markets Institutions, and Instruments, Vol. 14, No.3, pp.107-134.

Dimson, E., Marsh, P. and Staunton, M. (2002) Triumph of the Optimists: 101 Years of Global Investment Returns, Princeton University Press, USA.

Ibbotson, R.G., Milevsky, M.A., Chen, P. And Zhu, K.X. (2007) Lifetime Financial Advice: Human Capital, Asset Allocation, and Insurance, The Research Foundation of the CFA Institute, USA.

Kanakaratnam, A. and Yin, Y.P. (2004) Reforming the Sri Lankan Employees' Provident Fund: A Historical and Counterfactual Simulation Perspective, $7^{\text {th }}$ Annual Conference on Global Economic Analysis, Washington DC.

Karunarathne, W. (2005) Reforming the Formal Social Security System in Sri Lanka. Unpublished PhD Thesis, National University of Singapore, Singapore.

Karunarathne, W. and Goswami, R. (2002) Reforming formal social security systems in India and Sri Lanka. International Social Security Review, Vol.55, No. 4, pp.89-106.

Markovitz, H. (1952) Portfolio Selection. Journal of Finance, Vol.7, No.1, pp.77-91.

Pfau, W. D. (2009) The Role of International Diversification in Public Pension Systems: The Case of Pakistan. Economic Issues. Vol. 14, No. 2, pp. 81-105.

Pfau, W. D. and Atisophon, V. (2009) The Impact of the National Pension Fund on the Suitability of Elderly Pensions in Thailand. Asian Economic Journal, Vol. 23, No. 1 pp. 41-63.

Reisen, H. (1997) Liberalizing Foreign Investments by Pension Funds: Positive and Normative Aspects. World Development, Vol.25, No.7, pp.1173-1182.

Ross, S.G. (2004) Collection of social contributions: Current practice and Critical Issues. International conference on changes in the structure and organization of social security administration, Cracow, Poland, 3-4 June.

Roy, A.D. (1952) Safety First and the Holding of Assets. Econometrica, Vol. 20, No.3, pp.431-449.

Solnik, Bruno, and Dennis McLeavey (2009) Global Investments, Sixth Edition, Pearson Prentice Hall, Boston. 
Figure 1: A Comparison between Total EPF Investment and the Domestic Equity Market Capitalization of Sri Lanka at Year End (1995-2009)

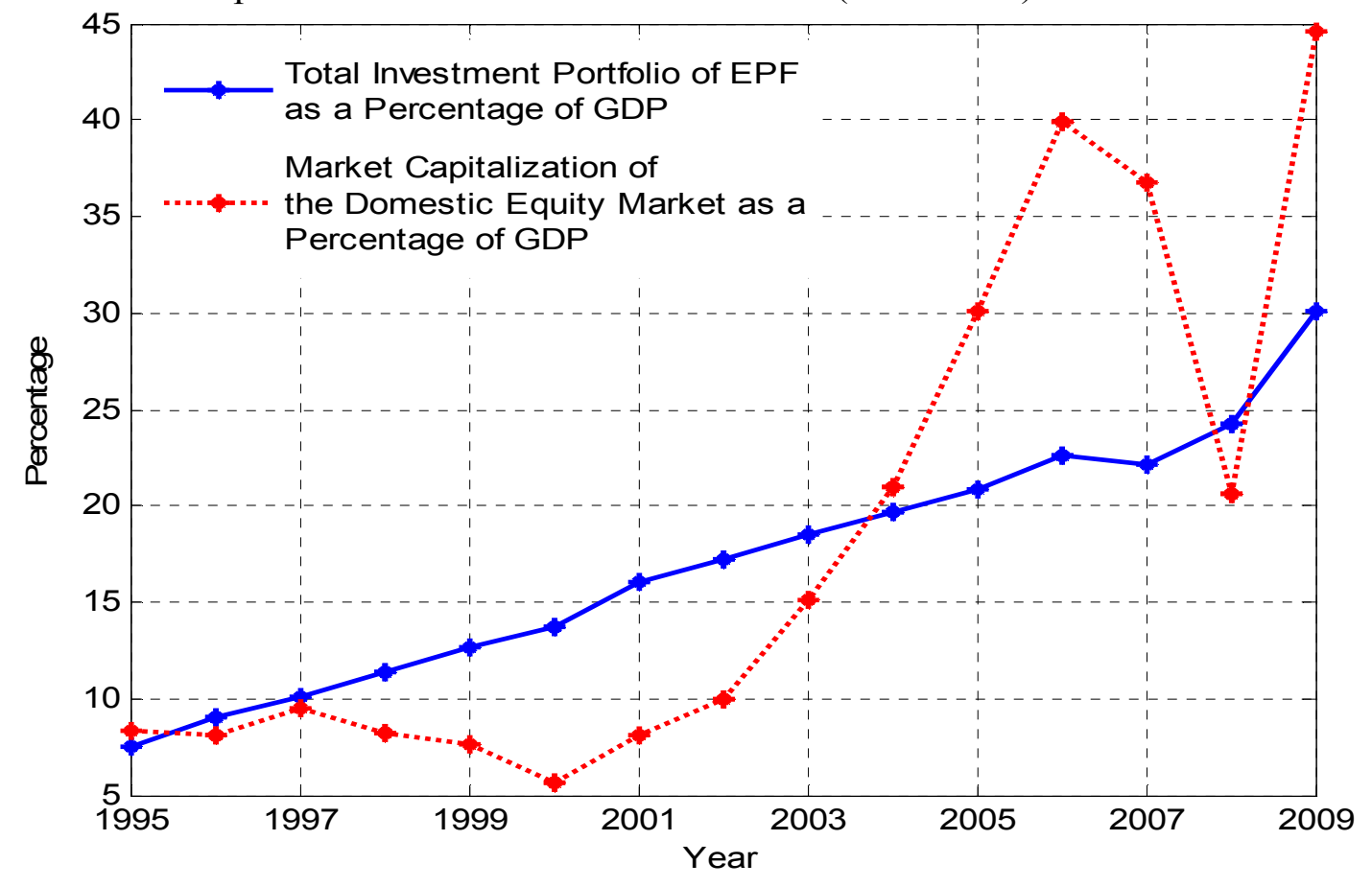

Source: Various issues of EPF Annual Reports, Colombo Stock Exchange, and Central Bank of Sri Lanka 
Table 1: EPF Investment Portfolio and Returns

\begin{tabular}{|c|c|c|c|c|c|c|c|c|c|}
\hline \multirow[t]{2}{*}{ Year } & \multicolumn{5}{|c|}{ Portfolio Structure } & \multicolumn{4}{|c|}{ Rate of Return } \\
\hline & $\mathrm{RL}$ & TBill & TBond & Equity & $\mathrm{O}$ & $\mathrm{BR}$ & NR & Difference & $\mathrm{RR}$ \\
\hline 1985 & 96.8 & 0.0 & 0.0 & 0.0 & 3.2 & 14.0 & 13.4 & -0.6 & 11.7 \\
\hline 1986 & 97.5 & 0.0 & 0.0 & 0.0 & 2.5 & 12.0 & 13.2 & 1.2 & 4.8 \\
\hline 1987 & 97.9 & 0.0 & 0.0 & 0.0 & 2.1 & 12.0 & 13.0 & 1.0 & 4.9 \\
\hline 1988 & 97.8 & 0.0 & 0.0 & 0.0 & 2.2 & 11.0 & 12.8 & 1.8 & -1.1 \\
\hline 1989 & 98.3 & 0.0 & 0.0 & 0.0 & 1.7 & 11.0 & 12.4 & 1.4 & 0.7 \\
\hline 1990 & 96.3 & 2.7 & 0.0 & 0.0 & 1.0 & 13.1 & 12.8 & -0.3 & -7.1 \\
\hline 1991 & 97.4 & 2.1 & 0.0 & 0.0 & 0.5 & 14.1 & 13.3 & -0.8 & 1.0 \\
\hline 1992 & 97.8 & 1.9 & 0.0 & 0.0 & 0.3 & 15.1 & 13.7 & -1.4 & 2.0 \\
\hline 1993 & 96.9 & 2.1 & 0.0 & 0.0 & 1.0 & 16.1 & 15.1 & -1.0 & 3.0 \\
\hline 1994 & 95.9 & 2.8 & 0.0 & 0.0 & 1.3 & 14.1 & 15.4 & 1.3 & 6.5 \\
\hline 1995 & 96.6 & 1.8 & 0.0 & 0.0 & 1.6 & 14.1 & 15.3 & 1.2 & 7.0 \\
\hline 1996 & 95.5 & 2.2 & 0.0 & 0.0 & 2.3 & 13.1 & 14.8 & 1.7 & -0.9 \\
\hline 1997 & 93.2 & 2.7 & 2.3 & 0.0 & 1.8 & 11.2 & 14.0 & 2.8 & 4.0 \\
\hline 1998 & 89.2 & 1.6 & 7.2 & 0.2 & 1.8 & 11.4 & 13.9 & 2.5 & 4.1 \\
\hline 1999 & 81.5 & 1.5 & 14.5 & 0.3 & 2.2 & 12.1 & 13.1 & 1.0 & 8.0 \\
\hline 2000 & 73.2 & 2.2 & 22.0 & 0.6 & 2.0 & 12.9 & 12.9 & 0.0 & 6.4 \\
\hline 2001 & 72.1 & 1.1 & 24.7 & 0.6 & 1.5 & 13.5 & 13.1 & -0.4 & -1.0 \\
\hline 2002 & 61.0 & 0.9 & 35.5 & 0.5 & 2.1 & 12.3 & 13.6 & 1.3 & 3.7 \\
\hline 2003 & 40.7 & 1.5 & 56.1 & 0.4 & 1.3 & 7.2 & 13.7 & 6.5 & 6.9 \\
\hline 2004 & 20.6 & 1.3 & 76.1 & 0.5 & 1.5 & 8.4 & 11.6 & 3.2 & 3.7 \\
\hline 2005 & 13.8 & 1.1 & 82.9 & 0.8 & 1.4 & 11.2 & 10.9 & -0.3 & -0.6 \\
\hline 2006 & 11.9 & 1.0 & 84.0 & 0.8 & 2.3 & 13.9 & 10.6 & -3.3 & -2.7 \\
\hline 2007 & 12.9 & 0.9 & 82.7 & 1.4 & 2.1 & 12.6 & 12.7 & 0.1 & -4.1 \\
\hline 2008 & 10.9 & 0.7 & 86.0 & 1.1 & 1.3 & 20.1 & 13.8 & -6.3 & -7.2 \\
\hline \multicolumn{6}{|c|}{ Arithmetic Mean } & 12.8 & 13.3 & 0.5 & 2.2 \\
\hline \multicolumn{6}{|c|}{ Geometric Mean } & 12.5 & 13.2 & 0.5 & 2.1 \\
\hline
\end{tabular}

Note: RL=Rupee Loans; TBill=Sri Lanka Bills; TBond=Sri Lanka Bonds; Equity=Sri

Lanka Equities; $\mathrm{O}=$ others; $\mathrm{BR}=$ Benchmark Returns; $\mathrm{NR}=$ Nominal return on average investments; Difference=NR-BR; RR=Real Return on average investments.

Return on average investments is defined as the year's investment income divided by the average of the fund's assets at start and end of the year.

Benchmark return is the weighted average return of rupee loans, Sri Lanka bills, and Sri Lanka bonds.

Source: Various issues of EPF Annual Reports 
Table 2: Summary Statistics for Historical Economic Data (Annual Data, 1991-2007)

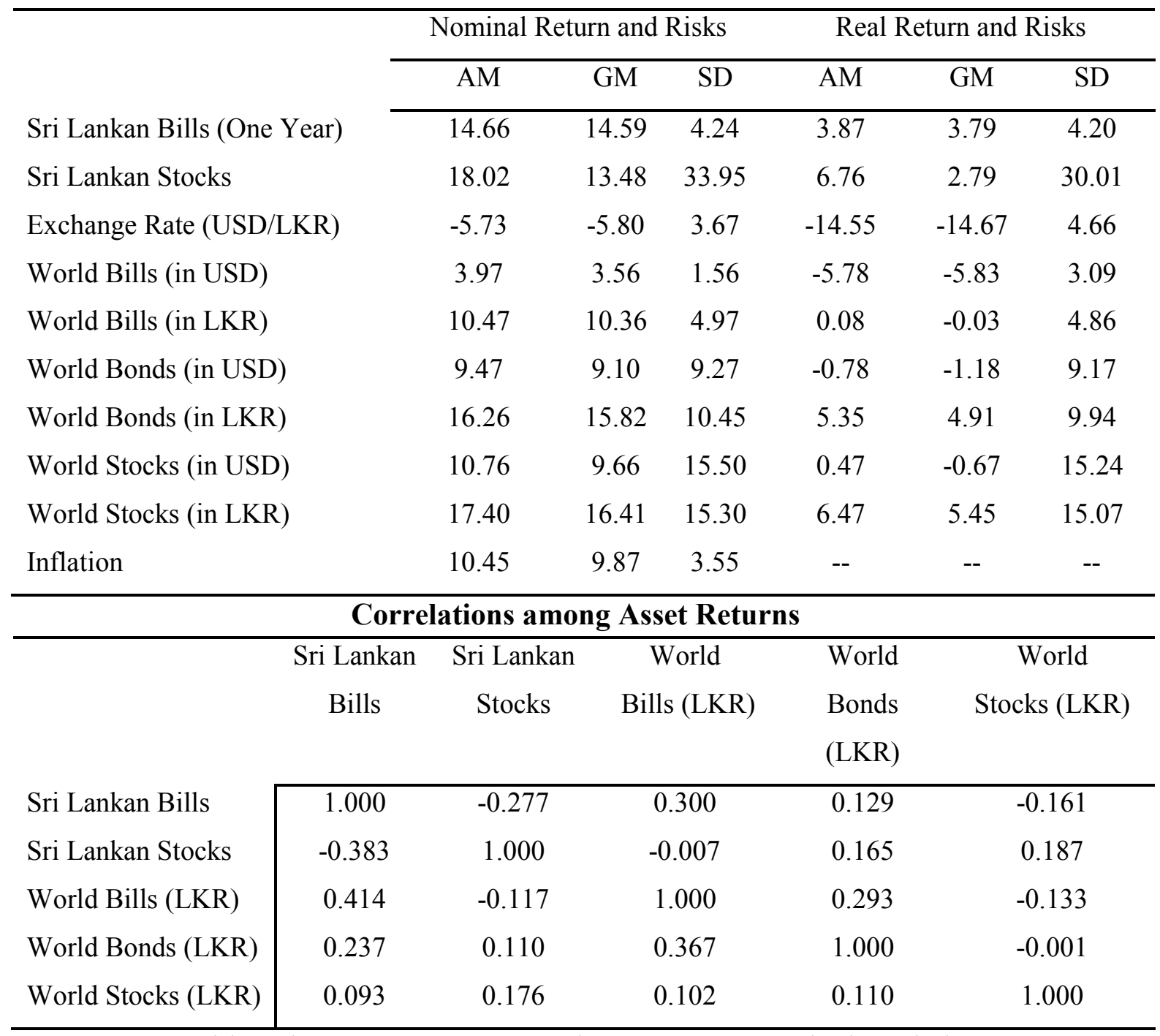

Note: $\mathrm{AM}=$ Arithmetic Mean, $\mathrm{GM}=$ Geometric Mean, $\mathrm{SD}=$ Standard Deviation.

Upper triangle of correlation coefficient matrix represents nominal returns, while lower triangle represents real returns.

Source: Own calculations based on time series economic data, 1991-2007 
Table 3: Fixed Asset Allocation Strategies for Sri Lankan EPF for Varying Degrees of Risk Aversion, Based on Annual Data, 1991-2007

\begin{tabular}{|c|c|c|c|c|c|c|}
\hline \multicolumn{7}{|c|}{ With Nominal Data } \\
\hline & \multicolumn{6}{|c|}{ Risk Aversion Coefficient } \\
\hline & & 2 & 3 & 4 & 5 & 10 \\
\hline Return (\%) & 17.16 & 16.89 & 16.56 & 16.19 & 15.97 & 15.53 \\
\hline Risk (\%) & 11.27 & 9.35 & 7.91 & 6.40 & 5.57 & 4.20 \\
\hline \multicolumn{7}{|l|}{ Portfolio Weights (\%) } \\
\hline Sri Lankan Treasury Bills & 0.00 & 0.00 & 12.91 & 30.36 & 40.84 & 61.78 \\
\hline Sri Lankan Stocks & 12.04 & 6.18 & 4.65 & 4.24 & 3.99 & 3.50 \\
\hline World Bills & 0.00 & 0.00 & 0.00 & 0.00 & 0.00 & 0.00 \\
\hline World Bonds & 28.09 & 48.06 & 45.04 & 35.32 & 29.49 & 17.83 \\
\hline World Stocks & 59.87 & 45.76 & 37.40 & 30.08 & 25.68 & 16.89 \\
\hline Percent Stocks & 71.91 & 51.94 & 42.05 & 34.31 & 29.67 & 20.39 \\
\hline Percent International & 87.96 & 93.82 & 82.44 & 65.40 & 55.17 & 34.72 \\
\hline \multicolumn{7}{|c|}{ With Real Data } \\
\hline & \multicolumn{6}{|c|}{ Risk Aversion Coefficient } \\
\hline & 1 & 2 & 3 & 4 & 5 & 10 \\
\hline Return (\%) & 6.22 & 5.96 & 5.65 & 5.26 & 5.03 & 4.57 \\
\hline Risk (\%) & 11.26 & 9.39 & 8.03 & 6.49 & 5.63 & 4.23 \\
\hline \multicolumn{7}{|l|}{ Portfolio Weights (\%) } \\
\hline Sri Lankan Treasury Bills & 0.00 & 0.00 & 12.65 & 32.12 & 43.80 & 67.16 \\
\hline Sri Lankan Stocks & 13.81 & 8.68 & 7.26 & 6.98 & 6.81 & 6.48 \\
\hline World Bills & 0.00 & 0.00 & 0.00 & 0.00 & 0.00 & 0.00 \\
\hline World Bonds & 26.03 & 47.67 & 45.77 & 34.86 & 28.32 & 15.23 \\
\hline World Stocks & 60.16 & 43.66 & 34.32 & 26.03 & 21.07 & 11.13 \\
\hline Percent Stocks & 73.97 & 52.33 & 41.58 & 33.02 & 27.88 & 17.61 \\
\hline Percent International & 86.19 & 91.32 & 80.09 & 60.89 & 49.39 & 26.37 \\
\hline
\end{tabular}

Source: Own calculations based on historical economic data, 1991-2007 
Table 4: The Impact of Constraints on Sri Lankan Asset Allocation for Varying Degrees of Risk Aversion, based on Annual Data, 1991-2007

\begin{tabular}{|c|c|c|c|c|c|c|}
\hline \multicolumn{7}{|c|}{ With Nominal Data } \\
\hline & \multicolumn{6}{|c|}{ Risk Aversion Coefficient } \\
\hline & 1 & 2 & 3 & 4 & 5 & 10 \\
\hline \multicolumn{7}{|l|}{ Unconstrained Portfolio } \\
\hline Return $(\%)$ & 17.16 & 16.89 & 16.56 & 16.19 & 15.97 & 15.53 \\
\hline Risk (\%) & 11.27 & 9.35 & 7.91 & 6.40 & 5.57 & 4.20 \\
\hline \multicolumn{7}{|c|}{ Optimal Portfolio when World Assets are Prohibited } \\
\hline Return (\%) & 15.72 & 15.27 & 15.12 & 15.04 & 15.00 & 14.90 \\
\hline Percentage Change in Return & -8.39 & -9.63 & -8.74 & -7.12 & -6.11 & -4.00 \\
\hline Risk (\%) & 10.27 & 6.15 & 5.03 & 4.58 & 4.35 & 4.03 \\
\hline Percentage Change in Risk & -8.86 & -34.20 & -36.35 & -28.46 & -21.81 & -4.08 \\
\hline \multicolumn{7}{|c|}{ Constrained Portfolio Weights (\%) } \\
\hline Sri Lankan Treasury Bills & 68.52 & 81.95 & 86.42 & 88.66 & 90.00 & 92.69 \\
\hline Sri Lankan Stocks & 31.48 & 18.05 & 13.58 & 11.34 & 10.00 & 7.31 \\
\hline \multicolumn{7}{|c|}{ With Real Data } \\
\hline & \multicolumn{6}{|c|}{ Risk Aversion Coefficient } \\
\hline & 1 & 2 & 3 & 4 & 5 & 10 \\
\hline \multicolumn{7}{|l|}{ Unconstrained Portfolio } \\
\hline Return (\%) & 6.22 & 5.96 & 5.65 & 5.26 & 5.03 & 4.57 \\
\hline Risk (\%) & 11.26 & 9.39 & 8.03 & 6.49 & 5.63 & 4.23 \\
\hline \multicolumn{7}{|c|}{ Optimal Portfolio when World Assets are Prohibited } \\
\hline Return (\%) & 4.88 & 4.47 & 4.33 & 4.26 & 4.22 & 4.14 \\
\hline Percentage Change in Return & -21.50 & -25.01 & -23.30 & -19.00 & -16.11 & -9.44 \\
\hline Risk (\%) & 9.78 & 5.83 & 4.74 & 4.30 & 4.08 & 3.77 \\
\hline Percentage Change in Risk & -13.11 & -37.93 & -40.96 & -33.72 & -27.57 & -10.98 \\
\hline \multicolumn{7}{|c|}{ Constrained Portfolio Weights (\%) } \\
\hline Sri Lankan Treasury Bills & 65.02 & 79.27 & 84.01 & 86.39 & 87.81 & 90.66 \\
\hline Sri Lankan Stocks & 34.98 & 20.73 & 15.99 & 13.61 & 12.19 & 9.34 \\
\hline
\end{tabular}

Source: Own calculations based on historical economic data, 1991-2007 
Table 5: Unconstrained Asset Allocation for the EPF of Sri Lanka: Simulation Results for the Hypothetical Worker based on Varied Risk Aversion Coefficients

\begin{tabular}{lrrrrrr}
\hline & \multicolumn{5}{c}{ Risk Aversion Coefficient } \\
\cline { 2 - 6 } & 1 & 2 & 3 & 4 & 5 & 10 \\
\cline { 2 - 7 } Portfolio Weights (\%) & & & & & & \\
Sri Lankan Treasury Bills & 0 & 0 & 0 & 10 & 25 & 55 \\
Sri Lankan Stocks & 20 & 15 & 10 & 10 & 10 & 10 \\
World Bills & 0 & 0 & 0 & 0 & 0 & 0 \\
World Bonds & 0 & 35 & 45 & 45 & 35 & 20 \\
World Stocks & 80 & 50 & 45 & 35 & 30 & 15 \\
\hline Percent Stocks & 100 & 65 & 55 & 45 & 40 & 25 \\
Percent International & 80 & 85 & 90 & 80 & 65 & 35 \\
\hline Distribution of Retirement Nest-Egg & & & & & & \\
$1^{\text {st }}$ Percentile & 5.18 & 6.79 & 7.22 & 7.61 & 8.02 & 8.75 \\
$5^{\text {th }}$ Percentile & 6.96 & 8.48 & 8.82 & 9.14 & 9.39 & 9.80 \\
$10^{\text {th }}$ Percentile & 8.21 & 9.70 & 9.95 & 10.18 & 10.31 & 10.45 \\
$25^{\text {th }}$ Percentile & 11.21 & 12.12 & 12.24 & 12.18 & 12.04 & 11.60 \\
$50^{\text {th }}$ Percentile (Median) & 15.78 & 15.61 & 15.39 & 14.85 & 14.28 & 13.04 \\
$75^{\text {th }}$ Percentile & 22.79 & 20.22 & 19.53 & 18.34 & 17.15 & 14.78 \\
$95^{\text {th }}$ Percentile & 39.15 & 30.06 & 27.76 & 25.02 & 22.42 & 17.91 \\
\hline Minimum Nest-Egg & 3.13 & 4.72 & 5.21 & 5.54 & 6.15 & 7.00 \\
\hline Sourryyyyy
\end{tabular}

Source: Own calculations based on historical economic data, 1991-2007

Note: The nest-egg is calculated as the ratio of accumulated assets at retirement to the average of the five years of income before retirement. 
Table 6: The Impacts of Investment Constraints on Asset Allocation for the EPF of Sri Lanka: Simulation Results for the Hypothetical Worker based on Varied Risk Aversion Coefficients

\begin{tabular}{|c|c|c|c|c|c|c|}
\hline \multirow[b]{3}{*}{ Portfolio Weights (\%) } & \multicolumn{6}{|c|}{ Risk Aversion Coefficient } \\
\hline & 1 & 2 & 3 & 4 & 5 & 10 \\
\hline & & & & & & \\
\hline Sri Lankan Treasury Bills & 50 & 70 & 80 & 80 & 85 & 90 \\
\hline Sri Lankan Stocks & 50 & 30 & 20 & 20 & 15 & 10 \\
\hline \multicolumn{7}{|c|}{ Distribution of Retirement Nest-Egg and Impact of Constraints } \\
\hline $1^{\text {st }}$ Percentile & 4.54 & 6.84 & 8.04 & 8.04 & 8.44 & 8.69 \\
\hline Percentage Change & -12.36 & 0.74 & 11.36 & 5.65 & 5.24 & -0.69 \\
\hline $5^{\text {th }}$ Percentile & 5.99 & 7.98 & 8.93 & 8.93 & 9.27 & 9.42 \\
\hline Percentage Change & -13.94 & -5.90 & 1.25 & -2.30 & -1.28 & -3.88 \\
\hline $10^{\text {th }}$ Percentile & 6.91 & 8.75 & 9.53 & 9.53 & 9.81 & 9.86 \\
\hline Percentage Change & -15.83 & -9.79 & -4.22 & -6.39 & -4.85 & -5.65 \\
\hline $25^{\text {th }}$ Percentile & 9.17 & 10.34 & 10.67 & 10.67 & 10.72 & 10.64 \\
\hline Percentage Change & -18.20 & -14.69 & -12.83 & -12.40 & -10.96 & -8.28 \\
\hline $50^{\text {th }}$ Percentile (Median) & 12.76 & 12.51 & 12.15 & 12.15 & 11.92 & 11.65 \\
\hline Percentage Change & -19.14 & -19.86 & -21.05 & -18.18 & -16.53 & -10.66 \\
\hline $75^{\text {th }}$ Percentile & 18.04 & 15.27 & 13.91 & 13.91 & 13.29 & 12.78 \\
\hline Percentage Change & -20.84 & -24.48 & -28.78 & -24.15 & -22.51 & -13.53 \\
\hline $95^{\text {th }}$ Percentile & 31.07 & 20.86 & 17.15 & 17.15 & 15.67 & 14.71 \\
\hline Percentage Change & -20.64 & -30.61 & -38.22 & -31.45 & -30.11 & -17.87 \\
\hline Minimum Nest-Egg & 2.49 & 5.03 & 6.22 & 6.22 & 6.84 & 7.32 \\
\hline
\end{tabular}

Source: Own calculations based on historical economic data, 1991-2007

Note: Percentage Change refers to the percentage change from the corresponding unconstrained value at that distribution percentile. 